\title{
Erratum to: Trans Women Doing Sex in San Francisco
}

\author{
Colin J. Williams ${ }^{1} \cdot$ Martin S. Weinberg $^{2} \cdot$ Joshua G. Rosenberger $^{3}$
}

Published online: 17 June 2016

(c) Springer Science+Business Media New York 2016

\section{Erratum to: Arch Sex Behav \\ DOI 10.1007/s10508-016-0730-6}

In the Results section, the last header should not contain the word "Identities." The main header should simply be "Confirming/Changing Sexual Preference," and the subheaders should only be "Stability" and "Vacillations."

The online version of the original article can be found under doi:10.1007/s10508-016-0730-6.

Martin S. Weinberg

weinberm@indiana.edu

1 Department of Sociology, Indiana University—Purdue

University at Indianapolis, 425 University Boulevard,

Cavanaugh Hall 303, Indianapolis, IN 46202, USA

2 Department of Sociology, Indiana University, 1020 E. Kirkwood Ave., BH 744, Bloomington, IN 47405, USA

3 Department of Biobehavioral Health, Penn State University, 114 Biobehavioral Health Bldg., University Park, PA 16802, USA 